\title{
Male lower urinary tract symptoms associated with overactive bladder
}

\author{
Marcus J. Drake, MA, DM, FRCS \\ Senior Lecturer in Urology, University of Bristol, Bristol, UK
}

Cite as: Can Urol Assoc J 2012;6(5):S136-7. http://dx.doi.org/10.5489/cuaj.12202

\section{Abstract}

Lower urinary tract symptoms (LUTS) associated with overactive bladder $(\mathrm{OAB})$ are more likely to respond to antimuscarinic therapy than to alpha blockade. As such, initial treatment of men with storage symptoms should incorporate an antimuscarinic agent. For men who are truly refractory to current pharmacotherapies, there is emerging evidence to support the use of botulinum toxin A.

$\mathrm{F}$ or men with lower urinary tract symptoms (LUTS), alphablockers are a logical first-line therapy. However, their mechanism of action is such that they are effective primarily against obstructive voiding symptoms. Patients with an overactive bladder $(\mathrm{OAB})$ component, with storage symptoms, are not likely to respond fully to alpha blockade, but may respond to therapy with an antimuscarinic drug. Therefore, for individuals with LUTS suggestive of OAB pathophysiology, inclusion of an antimuscarinic in first-line therapy may be a more appropriate option. The following review provides a summary of the evidence supporting the use of antimuscarinics alone or in combination with alpha-blockers in male LUTS. In addition, the review includes strategies to consider for men with truly refractory LUTS.

\section{Antimuscarinics for male LUTS}

\section{Combination with alpha-blockers}

Clinical practice guidelines for male LUTS endorse the sequential use of antimuscarinics in combination with alpha-blockers for ongoing storage symptoms. ${ }^{1}$ This recommendation is supported by the results of the NEPTUNE study, a placebo-controlled trial evaluating tamsulosin alone or in combination with solifenacin in approximately 1,500 men with benign prostatic hyperplasia (BPH) and a substantial storage LUTS component. ${ }^{2}$ The co-primary study endpoints were changes in total International Prostate Symptom Score (IPSS) and total urgency score (TUS), from baseline to treatment end. Patients were randomized to one of four groups: tam-

sulosin oral controlled absorption system $0.4 \mathrm{mg}$ (TOCAS) + solifenacin $6 \mathrm{mg}$; TOCAS $0.4 \mathrm{mg}$ + solifenacin $9 \mathrm{mg}$; TOCAS $0.4 \mathrm{mg}$ alone or placebo.

All three active treatment groups showed statistically significant improvements in TUS versus placebo (Fig. 1). The TOCAS $0.4 \mathrm{mg}+$ solifenacin $6 \mathrm{mg}$ combination was significantly superior to TOCAS $0.4 \mathrm{mg}$ alone.

For the analysis of total IPSS, both doses of combination therapy and TOCAS $0.4 \mathrm{mg}$ alone showed significant improvements versus placebo. There was no significant difference between the combination and TOCAS monotherapy arms. The rates of treatment-emergent adverse events and urinary retention requiring catheterization were low.

The NEPTUNE trial also has an open-label extension study that has yet to be presented or published. Analysis of data from this extension study is expected to yield information on the long-term efficacy, safety and switch behaviour for combination therapy.

\section{Antimuscarinic monotherapy}

Although this approach is not recommended by clinical practice guidelines for initial therapy, it does make sense to consider it for patients with monosymptomatic OAB. Clinical trial evidence has demonstrated that antimuscarinic monotherapy is associated with significant improvements in symptoms compared to placebo. An analysis of 582 men pooled from four clinical trials in $\mathrm{OAB}$ showed that treatment with solifenacin 5 or $10 \mathrm{mg}$ daily was associated with reductions in urgency, incontinence and micturition frequency compared to placebo (Fig. 2). ${ }^{3}$

\section{Urinary retention}

The key issue of urinary retention risk relates to the concern that antimuscarinic therapy might counteract the ability of the innervation to mediate the detrusor contraction of voiding. In practice, short-term studies show a small increase of post-void residual and no increase in acute urinary retention, beyond what would be expected from natural history studies. ${ }^{4,5}$ 


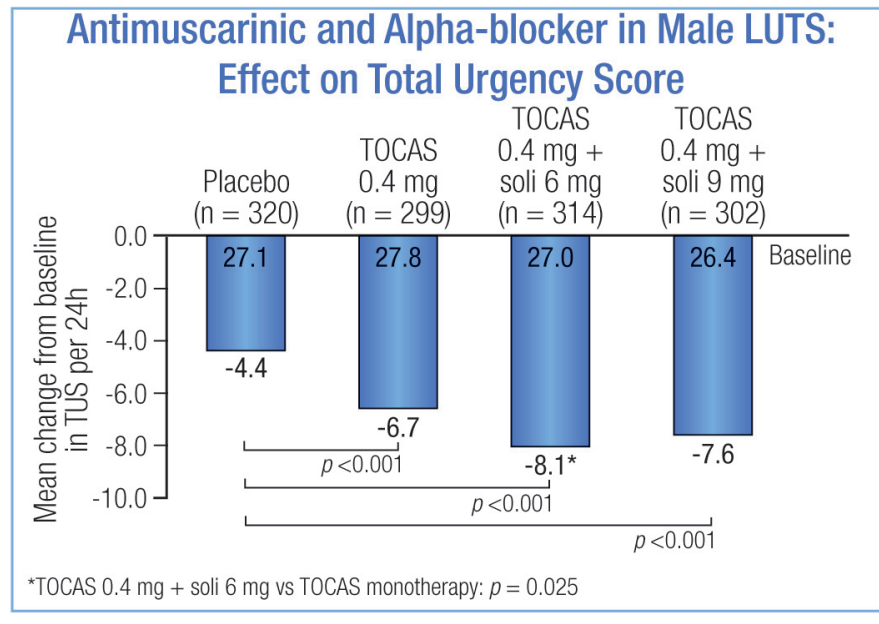

Fig. 1. Antimuscarinic + alpha-blocker in male lower urinary tract symptoms: Effect on total urgency score. TOCAS: tamsulosin oral controlled absorption system; sol: solifenacin.

\section{Refractory patients}

While antimuscarinic and/or alpha-blockade therapy is effective for symptom relief in a large proportion of patients with LUTS associated with $\mathrm{OAB}$, a substantial minority do not achieve adequate symptomatic treatment response.

In these cases, the clinician should consider whether the issue relates to additional symptoms (mixed LUTS), confounding mechanisms (polyuria, infection), behavioural factors, poorly responding symptoms (nocturia; nocturnal polyuria), or "alternative diagnoses." Attention to treatment compliance, conservative measures, and tailoring of antimuscarinic therapy (dose, combination and side-effect amelioration) can improve response.

\section{Other pharmacotherapeutic options}

The complex basic science offers scope for new therapeutic targets that aim to counteract triggering or propagation of overactivity. However, the systems physiology is of such complexity ${ }^{6,7}$ that targeting end organ excitability remains the foremost strategy. Botulinum toxin $\mathrm{A}$ injections have demonstrated efficacy in $\mathrm{OAB} ;$ beta ${ }_{3}$ agonists target another pathway that may also prove to be a therapeutic option in the foreseeable future. ${ }^{9}$

\section{Conclusions}

The approach to the management of male LUTS should be based on the symptomatology, with alpha-blocker monotherapy considered the best initial treatment for obstructive symptoms, antimuscarinic therapy for the storage symptoms of $\mathrm{OAB}$, and the combination of both agents for patients with LUTS of suspected mixed pathology.

For patients with $\mathrm{OAB}$ who are refractory to initial treatments (i.e., persistent urgency), consider alternative diagnoses and ensure correct implementation of both conservative measures and pharma-

\section{Antimuscarinic therapy helps storage LUTS}

Meta-analysis: subgroup analysis of 582 men from 4 RCTs (phase III) evaluating efficacy/safety of solifenacin (12 weeks) in OAB patients

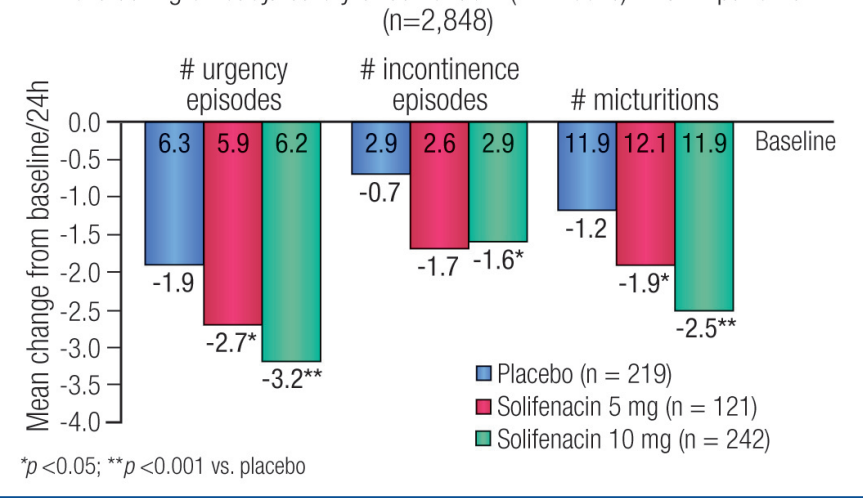

Fig. 2. Antimuscarinic monotherapy for men with overactive bladder.

cotherapy. Emerging pharmacotherapeutic options for truly refractory $\mathrm{OAB}$ include botulinum toxin $\mathrm{A}$ and beta agonists. $^{2}$

Competing interests: Prof. Drake is an ongoing paid consultant with Ferring. He has also received speaker fees, educational grants and/or travel assistance from Ferring, Allergan, Pfizer and Astellas within the last two years.

\section{References}

1. Oelke M, Bachmann A, Descazeaud A, et al. Guidelines on the Management of Male Lower Urinary Tract Symptoms (LUTS), incl. Benign Prostatic Obstruction (BPO). European Association of Urology, 2012. http://www.uroweb.org/gls/pdf/12_Male_LUTS_LR.pdf (Accessed July 31, 2012).

2. Drake $M$, Chapple $C$, van Kerrebroeck $P$, et al. Efficacy of combination therapy with tamsulosin OCAS and solifenacin in NEPTUNE: Results from a randomised, phase 3 trial in men with LUTS. Eur Urol 2012;EAU Abstracts \#746.

3. Van Kerrebroeck P, Steers W, Haab F. Establishing effective treatment of overactive bladder symptoms in men [abstract \#233]. Eur Urol Suppl 2005;3:61. http://dx.doi.org/10.1016/S15699056(05)80241-6

4. Abrams P, Kaplan S, De Koning Gans HJ, et al. Safety and tolerability of tolterodine for the treatment of overactive bladder in men with bladder outlet obstruction. J Urol 2006;175(3P+1):999-1004. http:// dx.doi.org/10.1016/S0022-5347(05)00483-0

5. Lee KS, Choo MS, Kim DY, et al. Combination treatment with propiverine hydrochloride plus doxazosin controlled release gastrointestinal therapeutic system formulation for overactive bladder and coexisting benign prostatic obstruction: a prospective, randomized, controlled multicenter study. I Urol 2005;174(4Pt1):1334-8. http://dx.doi.org/10.1097/01.ju.0000173630.94559.fd

6. Birder L, de Groat W, Mills $\mathrm{I}$, et al. Neural control of the lower urinary tract: peripheral and spinal mechanisms. Neurourol Urodyn 2010;29:128-39. http://dx.doi.org/10.1002/nau.20837

7. Drake MJ, Fowler CJ, Griffiths D, et al. Neural control of the lower urinary and gastrointestinal tracts: supraspinal CNS mechanisms. Neurourol Urodyn 2010;29:119-27. http://dx.doi.org/10.1002/ nau.20841

8. Oliver A, Drake M. Refractory Urgency and Urgency Incontinence. Pelvic Floor Clinical Studies Group. http://www.pfcsg.org.uk/ (Accessed July 31, 2012).

9. Tyagi P, Tyagi V. Mirabegron, a $\beta_{3}$-adrenoceptor agonist for the potential treatment of urinary freq-uency, urinary incontinence or urgency associated with overactive bladder. IDrugs 2010;13:713-22.

Correspondence: Prof. Marcus Drake, Consultant Urological Surgeon, Bristol Urological Institute, Southmead Hospital, Bristol BS10 5NB, UK; marcus.drake@bui.ac.uk 